\title{
Interactive comment on "Characterizing quasi-biweekly variability of the Asian monsoon anticyclone using potential vorticity and large-scale geopotential field" by Arata Amemiya and Kaoru Sato
}

Anonymous Referee \#1

Received and published: 9 July 2020

Please find my review comments in the attached report.

Please also note the supplement to this comment: https://www.atmos-chem-phys-discuss.net/acp-2020-424/acp-2020-424-RC1supplement.pdf 